\title{
Hypertrophic Osteoathropathy without Pachyderma in a Nigerian: A Case Report
}

\author{
Adamu G. Umar1*, Philip B. Adebayo2,3, Abdullahi A.4, Ibok I. Okon1, Umenze Ikenna1 \\ ${ }^{1}$ Department of Medicine, Federal Medical Centre, Bida, Nigeria \\ ${ }^{2}$ Department of Medicine, Ladoke Akintola University of Technology, Ogbomoso, Nigeria \\ ${ }^{3}$ Department of Medicine, Ladoke Akintola University of Technology Teaching Hospital, Ogbomoso, Nigeria \\ ${ }^{4}$ Department of Nursing Services, General Hospital, Minna, Nigeria \\ Email: *ugadamu@yahoo.com, philipab8@yahoo.com, aabdullahi419@yahoo.com, \\ Okon-idyibok@yahoo.com, Ikenna-iyke2legit@yahoo.co.uk
}

Received 20 April 2015; accepted 26 June 2015; published 29 June 2015

Copyright (C) 2015 by authors and Scientific Research Publishing Inc.

This work is licensed under the Creative Commons Attribution International License (CC BY).

http://creativecommons.org/licenses/by/4.0/

(c) (i) Open Access

\begin{abstract}
Hypertrophic osteoathropathy is characterized by triad of digital clubbing, periostosis, and pachyderma. We report the case of a young male Nigerian with asymptomatic idiopathic digital clubbing with neither skin changes nor periosteal reaction. He presented to our hospital with swelling of fingers and toes of about six years' duration. All his fingers and toes were clubbed with drumstick appearance, no swelling or tenderness of the wrists, elbows, ankles or knees and no skin changes. The laboratory findings were normal. Primary hypertrophic osteoathropathy without pachydermia was entertained when neither skin changes nor periostosis were found. Although primary hypertrophic osteoathropathy without skin involvement is rare, effort should be made to search for secondary causes.
\end{abstract}

\section{Keywords}

Osteoarthropathy, Periostosis, Pachyderma, Idiopathic

\section{Introduction}

Primary hypertrophic osteoarthropathy (PHO) is a rare congenital disease that is inherited in an autosomal fashion. PHO is characterised by digital clubbing, arthropathy and periostosis of long tubular bones. The major conditions associated with hypertrophic osteoarthropathy are: pulmonary diseases $(75 \%-80 \%)$, cardiovascular abnormalities (10\% - 15\%), diseases of the liver and gastrointestinal tract (5\% - 15\%) and miscellaneous disord-

\footnotetext{
${ }^{*}$ Corresponding author.
}

How to cite this paper: Adamu, U.G., Adebayo, P.B., Abdullahi A., Okon, I.I. and Ikenna, U. (2015) Hypertrophic Osteoathropathy without Pachyderma in a Nigerian: A Case Report. World Journal of Cardiovascular Diseases, 5, 166-170. 
ers (5\% - 15\%) and in rare cases idiopathic [1] [2]. PHO may be familial in 25\% - 38\% of patients and has been reported in consanguineous marriages where the autosomal dominant form of inheritance has been implicated [3]. Three forms of PHO have been described that include the complete form with pachydermia, clubbing, perisostosis; the fruste form that has prominent pachydermia with minimal skeletal changes; and the incomplete form with no pachydermia [4].

The disease is more common in males and develops gradually from adulthood. Here, we report the case of a young male Nigerian with primary hypertrophic osteoarthropathy without skin involvement. To the best of our knowledge, a well investigated primary hypertrophic osteoarthropathy without pachyderma in a Nigerian has not been reported previously.

\section{Case Report}

A 40-year-old Nigerian presented to our hospital with swelling of fingers and toes of about six years' duration. The swelling is painless but has been gradually progressive. There was no associated chest pain, difficulty with breathing, palpitations or leg swelling. He had no history of cough, weight loss, neck swelling and no symptoms referable to the gastrointestinal system. He does not smoke nor drink alcoholic beverages. He has not been treated for any chronic ill health. There is no family history of digital clubbing. At presentation, he was nonobese young man with a normal body mass index of $19.5 \mathrm{~kg} / \mathrm{m}^{2}$ with a pulse rate of 72 beat per minute, respiratory rate 18 per minute, and blood pressure 110/80 mm $\mathrm{Hg}$. He was not pale, acyanosed, anicteric, and no significant peripheral lymphadenopathy. All the fingers (Figure 1) and toes (Figure 2) were clubbed with a drumstick appearance.

There was no notable swelling or tenderness of the wrists, elbows, ankles or knees and no thickening of the skin over the arms or legs. No neck swelling. Other systemic examination was uneventful. Full blood counts, urinalysis, and electrolytes, urea and creatinine were within normal limits. The thyroid and liver function tests were normal. Antibodies to hepatitis B (HBsAg), hepatitis C and Human immunodeficiency viruses were negative. Tuberculin skin test was negative. Chest radiograph and electrocardiogram were normal. A radiograph of the wrists and hands (Figure 3) as well as those of the long bones (Figure 4) did not reveal any evidence of new bone formation. Two-dimensional echocardiography including Doppler was essentially normal.

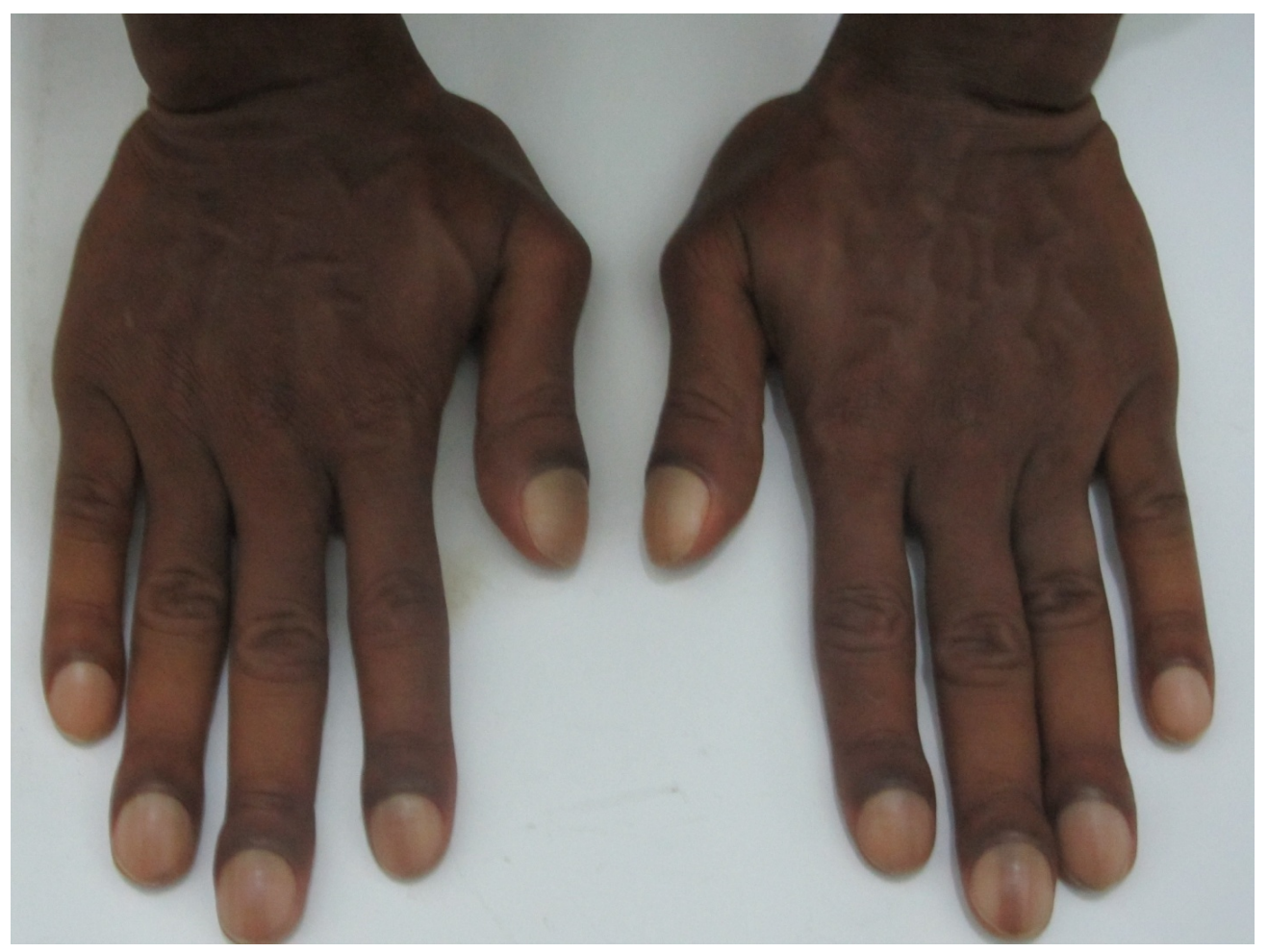

Figure 1. Clubbing of all the fingers. 


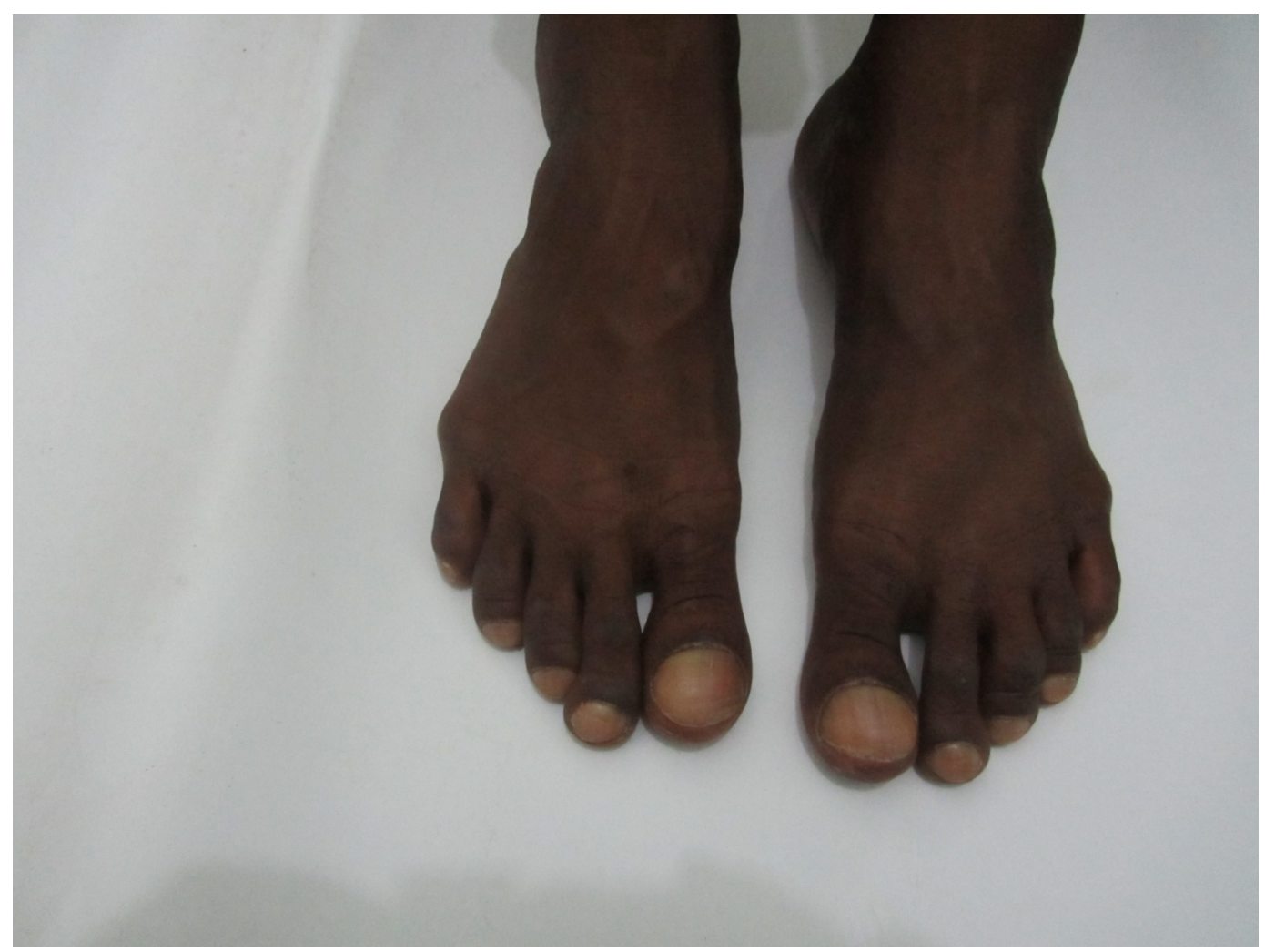

Figure 2. Clubbing of the toes.

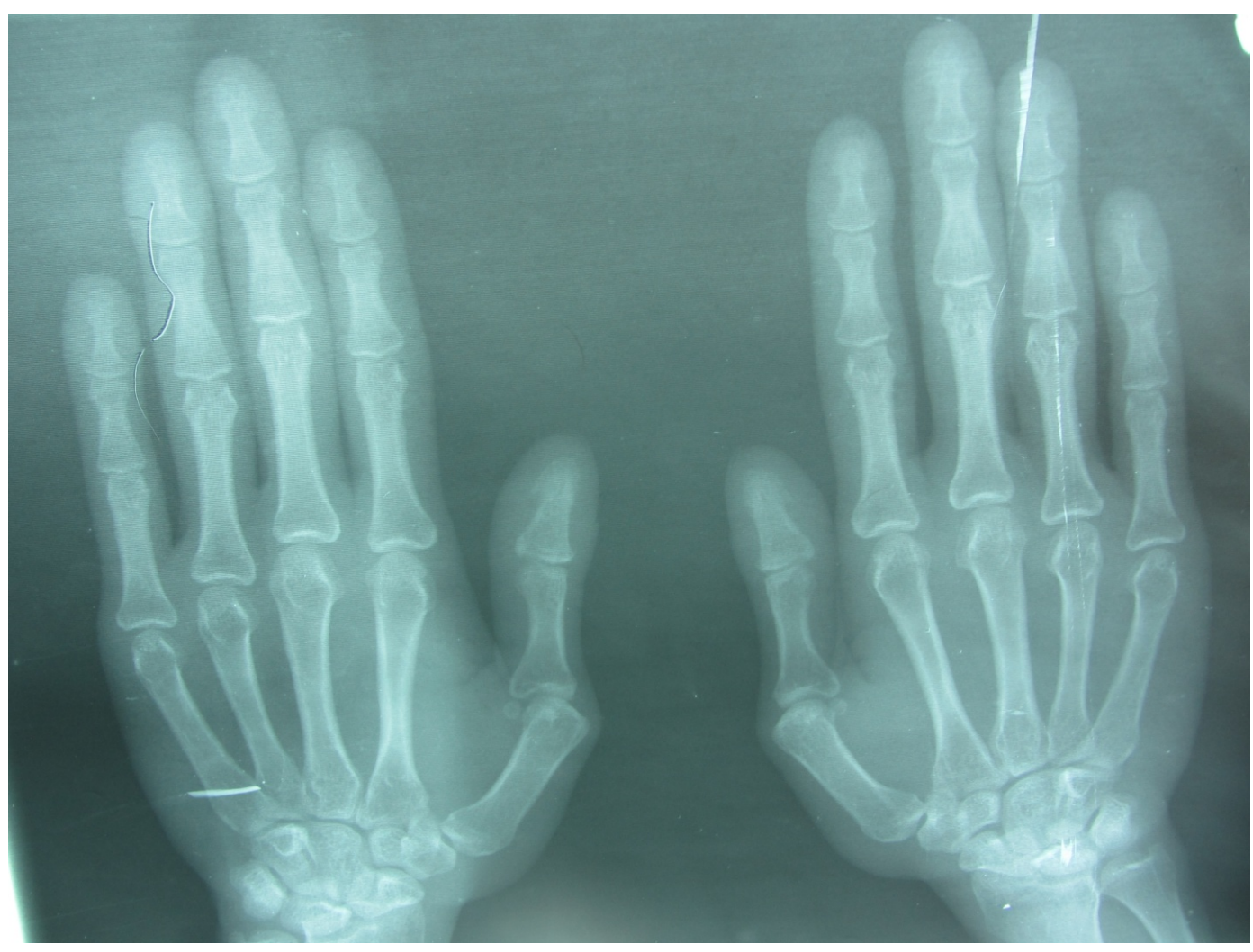

Figure 3. X-ray of both hands with no evidence of periostosis. 


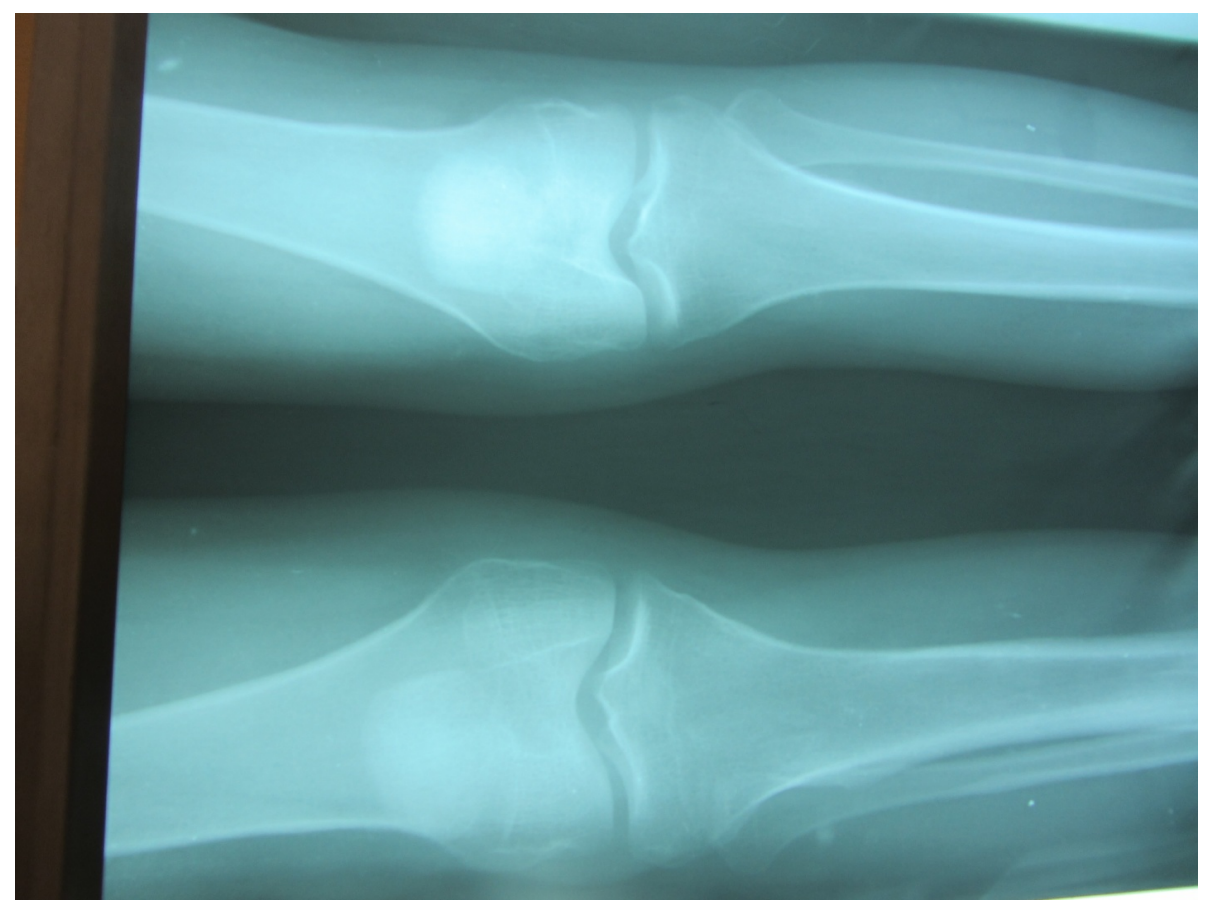

Figure 4. X-ray of the long bones.

\section{Discussion}

Digital clubbing also called drumstick fingers, watch-glass fingers/nails or Hippocratic fingers/nails was first described by Hippocrates about 2500 years ago [1]. It is characterized by focal bulbous swelling of the terminal segments of the fingers and/nails due to proliferation of the connective tissue between the nail matrix and the distal phalanx with resultant increase in their antero-posterior and the lateral diameters [2]. It is regarded as one of the oldest sign in medicine [5]. The prevalence of finger clubbing in the general population is not known, but a study by Vandemergel et al. [6] found a prevalence of about $1 \%$ of all patients admitted into a department of general internal medicine. Although digital clubbing often occur in patients with underlying medical conditions like malignancies, cyanotic congenital heart diseases, idiopathic pulmonary fibrosis and underlying suppurative lung disease etc, some cases have no known cause and hence classified as idiopathic or primary. In a Belgian study, $40 \%$ of admitted patients were found to have serious underlying medical problems after 1 year of follow up and in $60 \%$ no indications of disease were found in them [6]. In a study in Nigeria by MacFarlane et al, clubbing occurred in $21 \%$ of patients with pulmonary tuberculosis and noted associations with severity of disease, cavitary tuberculosis and hypoalbuminaemia [7].

The pathogenesis of digital clubbing is not known, however, fibroblasts proliferation and fibrillogenesis are the main focus of the fibrotic process, resulting in increased amount of collagen fibers [3] [8] [9]. Other suggested mechanisms include, dysregulation of the matrix molecules synthesized by the fibroblast with increased matrix deposits and increased synthesis of decorin in protein [8] [10], the higher levels of plasma growth hormone in patients than in controls [11], the return of the embryonic claw that was lost during evolution [12], and the release of platelets-derived growth factor by the trapped megakaryocytic and platelets and vascular endothelial growth factor in response to arterial hypoxaemia and subsequent increased vascularity, permeability and connective tissue changes [13].

The case reported was first seen by us about two and half years ago and underwent thorough medical examinations and various investigations. He has been on followed up and surveillance for any ill-health. He is in a very good state of health.

\section{Conclusion}

Although digital clubbing is often seen in association with cardiovascular, gastrointestinal, hepatic and pulmo- 
nary diseases, it should be remembered that, in few cases, it could be idiopathic. Effort should therefore be made to screen for them.

\section{Acknowledgements}

We want to express our thanks to Dr. Erinle SA, Radiologist, for his comments on the X-ray films.

\section{Consent}

Written informed consent was obtained from the patient for publication of this case report and accompanying images. A copy of the written consent is available for review by the Editor-in-Chief of this journal.

\section{Competing Interests}

The authors declare that they have no competing interests.

\section{Authors' Contributions}

All the authors of this article participated in the clinical work-up, medical photography, the literature search and the writing of the manuscript. All authors read and approved the final manuscript.

\section{References}

[1] Friedman, H.H. (2001) Clubbing. In: Friedman, M.H., Ed., Problem-Oriented Medical Diagnosis, 7th Edition, Lipponcpott Williams and Wilkins, Philadelphia, 277-278.

[2] Hansen-Flaschen, J. and Nordberg, J. (1987) Clubbing and Hypertrophic Osteoarthropathy. Clinics in Chest Medicine, 8, 287-298.

[3] Matucci-Cerinic, M., Lotti, T., Jajic, I., Pignone, A., Bussani, C. and Cagnoni, M. (1991) The Clinical Spectrum of Pachydermoperiostosis (Primary Hypertrophic Osteoarthropathy). Medicine, 70, 208-214. http://dx.doi.org/10.1097/00005792-199105000-00005

[4] Kerimovic-Morina, D.J. and Mladenovic, V. (1992) Primary Hypertrophic Osteoarthropathy in 32 Patients. Clinical and Experimental Rheumatology, 10, 51-56.

[5] Prognostic. In: Jones, W.H., Ed., Hippocartes, Vol. II, Loeb Classic Library No. 148.

[6] Vandemergel, X. and Renneboog, B. (2008) Prevalence, Aetiologies and Significance of Clubbing in a Department of General Internal Medicine. European Journal of Internal Medicine, 19, 325-329. http://dx.doi.org/10.1016/j.ejim.2007.05.015

[7] Macfarlane, J.T., Ibrahim, M. and Tor-Agbidye, S. (1979) The Importance of Finger Clubbing in Pulmonary Tuberculosis. Tubercle, 60, 45-48. http://dx.doi.org/10.1016/0041-3879(79)90055-2

[8] Kahaleh, M.B. (1992) The Role of Vascular Endothelium in Fibroblast Activation and Tissue Fibrosis, Particularly in Scleroderma (Systemic Sclerosis) and Pachydermoperiostosis (Primary Hypertrophic Steoarthropathy). Clinical and Experimental Rheumatology, 10, 45-48.

[9] Matucci-Cerinic, M., Sacerdoti, L., Perrone, C., Carossino, A., Cagnoni, M.L., Jajic, I. and Lotti, T. (1992) Pachydermoperiostosis (Primary Hypertrophic Osteoarthropathy): In Vitro Evidence for Abnormal Fibroblast Proliferation. Clinical and Experimental Rheumatology, 10, 57-60.

[10] Silveri, F., De Angelis, R., Argentati, F., Brecciaroli, D., Muti, S. and Cervini, C. (1996) Hypertrophic Osteoarthropathy: Endotheliumand Platelet Function. Clinical Rheumatology, 15, 435-439. http://dx.doi.org/10.1007/BF02229639

[11] Cosney, M.A., Cosney, J.R. and Lye, M. (1995) Carcinoma of the Bronchus. Thorax, 45, 545-547.

[12] Brouwers, A.A., Vermeij-Keers, C., van Zoelen, E.J. and Gooren, L.J. (2004) Clubbed Fingers: The Claws We Lost? Medical Hypotheses, 62, 321-324. http://dx.doi.org/10.1016/S0306-9877(03)00300-1

[13] Atkinson, S. and Fox, S.B. (2004) Vascular Endothelial Growth Factor (VEGF)-A and Platelet-Derived Growth Factor (PDGF) Play a Central Role in the Pathogenesis of Digital Clubbing. Journal of Pathology, 203, 721-728. http://dx.doi.org/10.1002/path.1565 